\title{
Investigating the Mediatory Role of Hope and Shame in the Relationship between Caregiver Burden and Quality of Life of Patients with Cancer
}

\author{
Touraj Shahvand ${ }^{1} \quad$ Mehdi Reza Sarafraz ${ }^{1}$ \\ ${ }^{1}$ Department of Clinical Psychology, Shiraz University, Shiraz, Iran
}

Address for correspondence Mehdi Reza Sarafraz, Assistant Professor, Department of Clinical Psychology, Shiraz University, Shiraz, Iran (e-mail: sarafrazmehdi9@gmail.com).

South Asian J Cancer 2020;9:174-179.

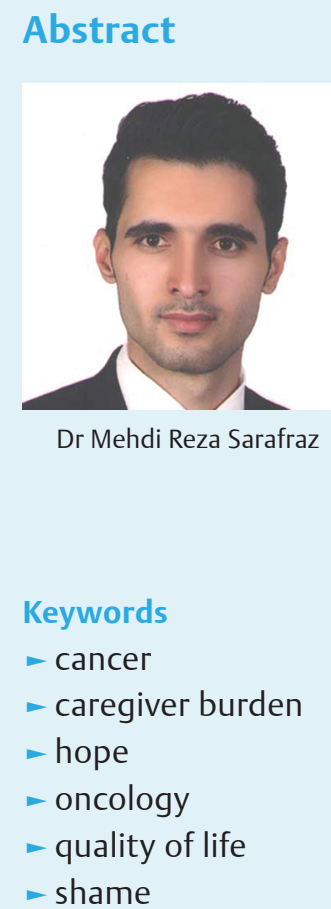

Objective Patients suffering from cancer need to receive care from their family; however, their family caregivers do this without preparation or training, so their involvement in patients' care results in a caregiving burden that may affect patient's hope and quality of life (QOL).

Materials and Methods This study examines the effect of caregiving burden on the QOL of cancer patients $(n=100)$ with the mediatory role of hope and shame. To achieve this, Persian versions of Zarit Burden Interview, the World Health Organization QOL, Herth Hope Index, and Guilt and Shame Proneness Scale were used. Meanwhile, path regression analysis was implemented to analyze the relationship between caregiving burden and QOL.

Results The results implied a relation among caregiver burden, hope, and $\mathrm{QOL}$ of patients diagnosed with cancer. It was found that there is a direct and negative relationship between caregiver burden and hope. In addition, there was an indirect and positive relationship between caregiver burden and QOL. Hope and QOL also had a high correlation. Besides, it was shown that there was a negative relationship between the shame experienced by patients and their hope and QOL.

Conclusion caregiver burden was proved to be influential and negatively affected the factor for the QOL. Besides, patients' hope decreases while caregiving burden increases; this will in turn affect patients' recovery and their physical, mental, and cognitive functions. This study provides a foundation for future research in this critical area for oncology.

\section{Introduction}

Cancer is a chronic disease that results in considerable, permanent, and variable needs and problems for patients. Because the unit of care in cancer care is the patient and family, ${ }^{1}$ investigation of the mutual effects of patient and caregiver relationship is of great significance in the process of sickness, therapy, and recovery.

Care is something that is neither predictable nor selected by people. When someone is confronted with cancer diagnosis

How to cite this article: Shahvand T, Sarafraz MR. Investigating the Mediatory Role of Hope and Shame in the Relationship between Caregiver Burden and Quality of Life of Patients with Cancer. South Asian J Cancer 2020;9(3):174-179.

DOI https://doi.org/10.1055/s-0041-1723109 ISSN 2278-330X. and therapy, his/her family members feel a high responsibility toward caregiving. ${ }^{2}$ Moreover, they are committed to offer infinite care and support. ${ }^{3}$ However, family members accept this responsibility with low or no training and limited resources. ${ }^{4}$ Caregiver burden is defined as the cognitive evaluation of the multidimensional response to demands and their consequences within the context of the evolving caregiving experience. ${ }^{5}$ Regarding cancer, the following variables are shown to be effective in the responsibility of caregiver: caregiver age and sex, relation to care receiver, and duration

(c) 2020. MedIntel Services Pvt Ltd.

This is an open access article published by Thieme under the terms of the Creative Commons Attribution-NonDerivative-NonCommercial-License, permitting copying and reproduction so long as the original work is given appropriate credit. Contents may not be used for commercial purposes, or adapted, remixed, transformed or built upon. (https://creativecommons.org/licenses/by-nc-nd/4.0/).

Thieme Medical and Scientific Publishers Private Ltd A-12, Second Floor, Sector -2, NOIDA -201301, India 
of care preparation. ${ }^{6}$ Caregiver burden includes physical burden, ${ }^{7}$ psychological burden, ${ }^{8}$ social burden, ${ }^{8}$ and financial burden. ${ }^{9}$ Physical burden such as sleep disturbance, fatigue, and pain are often experienced by caregivers. ${ }^{7}$ Providing emotional support to patients and helping cancer patients to deal with their feelings about cancer are considered as psychological commitments. ${ }^{8}$ Lack of employment due to caregiving activities and taking care of others besides cancer patients are known as social responsibilities. ${ }^{10}$ Financial burden might include high medical expenses, loss of income, and savings. ${ }^{8}$ In an extensive review of literature, Schulz et al reviewed 41 studies and reported high physical and psychological distemper of caregivers compared with normal populations or control group. ${ }^{11}$ In fact, most of the psychological distress levels reported by caregivers are comparable or even more than those experienced by care receivers. ${ }^{12}$

This study tries to identify whether the caregiver's distress affect the patient? if yes, how? It is assumed that caregiver burden affects patients' hope and QoL. Furthermore, it is predicted that patients can keep and raise their hope to control their environment, be less dependent on the caregiver, and recover faster. Recent studies have also shown that quality of life (QOL) can offer distinct prognostic information as a predictor for the recovery duration of different types of cancers. ${ }^{13}$

As a dynamic and multidimensional structure, hope is affected by various factors, and it is defined as the likelihood of better future than a hard and uncertain present. ${ }^{14}$ Identifying factors that influence the hope of newly diagnosed cancer patients is of great importance as hopelessness is a risk factor that may lead to suicide, ${ }^{15}$ depression, and tendency to early death ${ }^{16}$ in cancer patients. Energy and pain levels are among the physical features effective in hope. Energy is considered one of the features of hope, and it is discovered that low energy has a significant relation to hope. ${ }^{17}$ The involvement of pain in the daily life of cancer patients has an inverse relation to their level of hope..$^{18}$ It is also found that psychological factors such as depression and anxiety are related to hope. ${ }^{19}$ An integrative literature review conducted by Lin and Bauer-Wu' $\mathrm{Wu}^{20}$ identified that living with hope and goal is the main element of psychospiritual well-being in terminal patients. Moreover, with this enhanced sense of psychospiritual well-being, patients can face a terminal disease more effectively.

The life quality of cancer survivors shows their therapy pattern and psychophysical functions that may be used to discover patients' subgroups in need of more surveillance and directive perspectives for patient-based interventions after the completion of cancer therapy. ${ }^{21}$ Although most cancer survivors cannot retain their physical, psychological, and social functions as before cancer therapy, some specific subgroups of them are at risk of decreased QOL even after 5 years of early diagnosis. ${ }^{22}$

It also seems that caregivers' negative evaluation, whether real or as perceived by patients, may lead to the feeling of shame in the very same patients. Hence, in individuals suffering from cancer who have low ability to control life events, behavioral compensation is not possible, negative evaluation of caregiver is predictable, and feeling shame is inevitable. Thus, studying the effect of the shame felt by the patient on hope and QOL elements is another goal of this research.
The feeling of shame has been studied in psychological theories and has been implicated in lots of psychopathological conditions. Shame is associated with a general punitive judgment of the self, which results in an intense emotional response and a tendency to withdraw and hide. ${ }^{23}$ Shame is also defined as a self-conscious negative emotion about self or personal self-blame. ${ }^{24}$

\section{Conclusion}

This study is a novel and important step to exploring the role of shame and hope as cardinal features in the cancer patients' experiences and presenting a composite picture of their quality of life affected by caregiver burden.

\section{Methods}

This research was conducted with patient-caregiver dyads to identify the different views of cancer patients and their caregivers. The patients and caregivers were allowed to complete the research form in multiple settings as needed and to ask assistance from a friend or an intimate person to answer the questionnaire. The patients' form and caregivers' form needed 15 minute and 5 minutes to be completed, respectively. They included valid survey tools and demographic information. The medical reports of patients were not evaluated. In fact, information reported by the individuals themselves was used. The inclusion criteria for patients were (1) older than 18 years, (2) being diagnosed with cancer, (3) being under therapy or follow-up at present, and (4) being in an appropriate physical and mental state to fill the questionnaire. A caregiver was defined as a family member or a close relative who had the highest responsibility to take care of the cancer patient and spend most of his or her time with the patient. Caregivers younger than 18 years or those with severe cognitive disorder were disregarded from the research.

The following four valid questionnaires were used in this study.

\section{Zarit Burden Interview}

Zarit $^{25}$ was the first author who offered an operational definition of caregiver burden. He designed a tool called Zarit Burden Interview (ZBI) for evaluating perceived caregiver burden. It consists of 22 questions that are rated on a scale from 0 to 4 based on the presence or severity of positive response. It measures caregiver health, psychological well-being, social life, financial status, and patient-caregiver relationship. The ZBI is translated into many languages, and its internal consistency is reported between 0.85 and $0.94 .^{26}$

\section{Guilt and Shame Proneness Scale}

The Guilt and Shame Proneness Scale ${ }^{27}$ is a 16-item, 7-point scale ( 1 = very unlikely and 7 = very likely), which measures individuals' variance in the tendency to experience guilt and shame. It consists of four subscales of guilt-negative behavior evaluation, guilt-repair, shame-negative self-evaluation (NSE), and shame-withdraw. The $\alpha$ coefficients tend to show lower reliability in scenario-based measures because each 
item consists of a unique variance for the scenario ${ }^{28}$; thus, the reliability was in the range of 0.61 to $0.69 .{ }^{27}$ In this study, shame subscales were only used and guilt subscales were removed as they were not related to the study purpose.

\section{Quality of Life-C 30}

$\mathrm{QOL}^{29}$ is a questionnaire designed by the European Organization for Research and Treatment of Cancer to measure the physical, mental, and social functions of cancer patients. It consists of five functional domains, three sign scales, a general health domain, and six individual items. The internal reliability of the questionnaire obtained by Cronbach's $\alpha$ is in the range of 0.56 to 0.85 and 0.84 in Cankurtaran et al's research ${ }^{30}$ and Tan et al's research, ${ }^{31}$ respectively.

\section{Herth Hope Index}

The Herth Hope Index ${ }^{32}$ is a 12-item, 4-point Likert scale ( 1 = completely disagree and $4=$ completely agree) that was designed to evaluate the rate of hope in adults based on clinical cases. It suggests three factors of hope namely (a) temporality and future, (b) positive readiness and expectancy, and (c) interconnectedness. The total rate is in the range of 12 to 84. Higher rates imply higher levels of hope. The $\alpha$ coefficient was 0.97 with a 2 -week test-retest reliability of 0.91 .

\section{Results}

Patients and caregivers are considered as a dyad when the two parties are willing to participate in the study and only after they have completed the consent form consciously and separately. Patients and their caregivers were evaluated by a trained interviewer in the hospital. The goal and research process were explained by the interviewer. Of 176 dyads requested to participate, 141 dyads accepted (participation rate: $80.11 \%$ ). If there was any nonreplied item in the questionnaire, those dyads were omitted from the analysis $(n=41)$. As a result, 100 dyads were included in the final analysis. For this study, patients were selected from Namazi and Shahid Mohammadi Hospital in Shiraz and Bandar Abbas, respectively.

The patient characteristics are summarized in - Table 1 . The current study was conducted on 46 men and 53 women (1 missing), with the diagnosis of cancer. In the "severity" section, much data were not completed that may be due to the low education level of the patients and their lack of awareness of their status. In addition, the percentage of cancer type among participants is summarized in - Table 1 . According to - Table 1, leukemia and liver cancer had the most and the least plentitude among the study individuals, respectively.

The mean, standard deviation, and correlation of research variables are summarized in - Table 2 . According to - Table 2, there is a significant correlation among exogenous, endogenous, and mediator variables, which made analysis completion possible. The direct and indirect effects are summarized in - Table 3. -Fig. 1 shows the relationships between the variables and the coefficients of the fitted model. The fitted indices obtained by route analysis employing maximum likelihood method showed the appropriate fitness of the pattern
Table 1 Patient characteristics $(n=100)$

\begin{tabular}{|l|l|}
\hline Characteristic & Value \\
\hline Age (y), mean \pm SD (range) & $45.1 \pm 16.3(21-80)$ \\
\hline Sex, $n$ (\%) & \\
\hline Male & $46(46)$ \\
\hline Female & $53(53)$ \\
\hline Marital status, $n$ (\%) & \\
\hline Married/living with partner & $66(66)$ \\
\hline Single/separated/divorced/widowed & $34(34)$ \\
\hline Education level, $n$ (\%) & \\
\hline Primary education & $34(34)$ \\
\hline High school & $31(31)$ \\
\hline University & $24(24)$ \\
\hline Other/unknown/uneducated & $11(11)$ \\
\hline Tumor classification, $n$ (\%) & \\
\hline Leukemia & $47(47)$ \\
\hline Prostate & $5(5)$ \\
\hline Breast & $19(19)$ \\
\hline Liver & $1(1)$ \\
\hline All others & $28(28)$ \\
\hline Severity, $n$ (\%) & $35(35)$ \\
\hline Low & $26(26)$ \\
\hline Mediate & $32(32)$ \\
\hline High & $7(7)$ \\
\hline Unknown & $1.1(0.08-11)$ \\
\hline Time since diagnosis, years (range) & \\
\hline Signed informed consentfor participation, $n(\%)$ & \\
\hline Yes & \\
\hline No & \\
\hline
\end{tabular}

Abbreviation: SD, standard deviation.

with data (Goodness-of-Fit Index $(\mathrm{GFI})=0.99$, Comparative Fit Index $(\mathrm{CFI})=0.99$, Adjusted Goodness-of-Fit Index (AGFI) $=0.94$, Incremental Fit Index $($ IFI $)=0.99$, Root Mean Squared Error of Approximation (RMSEA) $=0.03$, and Normed ChiSquare $($ CMIN/DF $)=1.07)$.

Caregiver burden negatively correlated with hope $(r=-0.28, p<0.01$ ) ( - Table 2). Moreover, in the model, hope ( $\beta=-0.22$ ) and QOL $(\beta=-0.10)$ both formed strong relations with caregiver burden ( - Table 3 and - Fig. 1 ).

Hope and shame-NSE subscale positively correlated with each other $(r=0.22, p<0.05)$ ( $>$ Table 2$)$. Furthermore, hope negatively correlated with shame-withdraw subscale $(r=-0.20, p<0.05)$ ( - Table 2). QOL was found to be statistically correlated $(r=0.34, p<0.01)$ ( - Table 2 ) and strongly related with hope $(\beta=0.35)$ ( $>$ Table 3 and $>$ Fig. 1 ).

Factors that positively correlated with shame-NSE subscale were QOL $(r=0.20, p<0.05)$ and shame-withdraw subscale $(r=0.25, p<0.05)$ ( - Table 2 ). The model suggests a positive regression between shame-NSE and shame-withdraw subscales $(\beta=0.28)$ ( $~-$ Table 3 and $=$ Fig. 1 ). 
Table 2 Mean, standard deviation, and correlation matrix

\begin{tabular}{|l|l|l|l|l|l|l|}
\hline Study Variables & Mean \pm SD & $\mathbf{1}$ & $\mathbf{2}$ & $\mathbf{3}$ & $\mathbf{4}$ & $\mathbf{5}$ \\
\hline 1. Shame-NSE & $20.89 \pm 5.54$ & 1 & & & \\
\hline 2. Shame-withdraw & $14.64 \pm 5.17$ & $0.255^{\mathrm{a}}$ & 1 & & & \\
\hline 3. Hope & $37.72 \pm 5.77$ & $0.223^{\mathrm{a}}$ & $-0.201^{\mathrm{a}}$ & 1 & & \\
\hline 4. Caregiver burden & $33.72 \pm 9.60$ & -0.112 & 0.177 & $-0.287^{\mathrm{b}}$ & 1 & \\
\hline 5. QOL & $-45.07 \pm 16.13$ & $0.205^{\mathrm{a}}$ & -0.100 & $0.349^{\mathrm{b}}$ & -0.188 & 1 \\
\hline
\end{tabular}

Abbreviations: QOL, quality of life; shame-NSE, shame-negative self-evaluation; SD, standard deviation. ${ }^{\mathrm{a}} p<0.05$.

${ }^{\mathrm{b}} \mathrm{p}<0.01$.

Table 3 Direct and indirect effects of variables

\begin{tabular}{|l|l|l|l|}
\hline Path & Direct effect & Indirect effect & Total effect \\
\hline Caregiver burden & & & -0.11 \\
\hline Shame-NSE & -0.11 & - & 0.18 \\
\hline Shame-withdraw & 0.21 & -0.3 & $-0.29^{\mathrm{b}}$ \\
\hline Hope & $-0.22^{\mathrm{a}}$ & $-0.07^{\mathrm{a}}$ & $-0.10^{\mathrm{b}}$ \\
\hline QOL & - & $-0.10^{\mathrm{b}}$ & $0.28^{\mathrm{b}}$ \\
\hline NSE & & & 0.20 \\
\hline Shame-withdraw & $0.28^{\mathrm{b}}$ & - & 0.07 \\
\hline Hope & $0.26^{\mathrm{a}}$ & $-0.06^{\mathrm{a}}$ & \\
\hline QOL & - & 0.07 & $-0.23^{\mathrm{a}}$ \\
\hline Shame-withdraw & & & $-0.08^{\mathrm{a}}$ \\
\hline Hope & $-0.23^{\mathrm{a}}$ & - & $-0.08^{\mathrm{a}}$ \\
\hline QOL & - & & $0.35^{\mathrm{b}}$ \\
\hline Hope & & - & \\
\hline QOL & $0.35^{\mathrm{b}}$ & & \\
\hline
\end{tabular}

Abbreviations: QOL, quality of life; shame-NSE, shame-negative self-evaluation. a $p<0.05$.

${ }^{\mathrm{b}} p<0.01$.

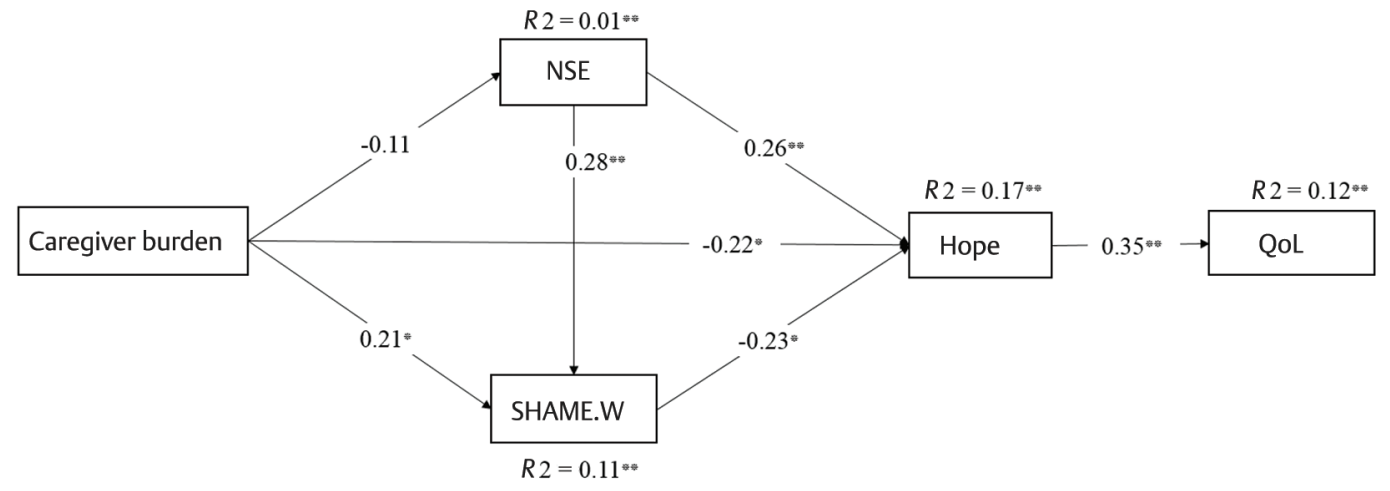

$$
* * p<0.01 * p<0.05
$$

Fig. 1 Structural equation model to assess the predictive manner of quality of life based on caregiver burden with the mediatory role of hope and shame. The one-headed arrow indicates a directional relationship between two variables. The number next to the arrow represents the relationship ( $\beta$ ). NSE, negative self-evaluation; QoL, quality of life. 
Descriptive statistics were implemented to assess demographic information and clinical characteristics. Data analysis was performed by using IBM Corp. Released 2015. IBM SPSS Statistics for Windows, Version 23.0. Armonk, NY, USA: IBM Corp. SPSS Statistics 23.0 for Windows and Amos Graphics Arbuckle, J. L. (2014). Amos (Version 23.0) [Computer program]. Chicago, USA: IBM Corp. 23.0 for Windows. To evaluate the validity of the research tool, Cronbach's $\alpha$ was used that was estimated to be over 0.70 for all questionnaires.

Before parametric statistical analysis, the data were analyzed with regard to consistency to substructural premises of this type of analysis. These premises are as follows: analyzing missed data, evaluating the normality of variables' data distribution, estimating outlier values' data, and the linearity of variables' relation. ${ }^{33}$ For measuring missed values and their probable pattern, missing value analysis algorithm was used. No missing values were found in any of the measures.

For the evaluation of variables' data normality, Kolmogorov-Smirnov and Shapiro-Wilk tests were used besides histogram diagram. According to the results, only the data of QOL and shame-withdraw variables followed normal distribution. For the variables that did not follow a normal distribution, data were transformed by Rankit formula ${ }^{34}$ and logarithm. ${ }^{33}$ After that, the distribution of hope and caregiver burden grades was normalized by using Box plot..$^{33}$ The outlier data recommended by Munro et $\mathrm{al}^{35}$ were corrected regarding the closest data to the outliers. The last step in data evaluation was investigating the premises of linear relation among the research variables. The presence of a linear relation among the variables was approved by a Scatter plot.

\section{Discussion}

The current study was performed to investigate the predictive model of QOL and hope based on caregiver burden and shame perceived by the patients. The suggested model was approved, and the results showed a negative and direct relationship between caregiver burden and hope. They also showed a positive and direct relationship between hope and QOL. The research hypothesis implied that caregiver burden predicts hope in patients with cancer and hope predicts their QOL. Shame was also significantly related to hope and QOL. Caregivers of cancer patients report that they spend more time in taking care of the patients and pay more efforts during a shorter period of time, besides they have to tolerate a higher financial burden compared with other caregivers. As a result, the more the patient percepts this burden, the less he/she will recover and the patient's hope will diminish faster. Caregiver characteristics that may lead to increase in burden include lower age, ${ }^{36}$ female gender, ${ }^{36}$ lower level of education, ${ }^{37}$ a mixed relation, ${ }^{38}$ and higher levels of anxiety and depression. ${ }^{39}$ Consequently, it is predicted that patients who are served by such caregivers have lower hope.

Caregiver burden has a negative and indirect effect on QOL with the mediatory role of hope. QOL includes physical, mental, and social elements of patients. Caregiver burden reduces the general health of patients. Recent studies have shown that QOL can bring a distinctive prognostic information to predict the recovery period of various cancers. Hence, as the caregiver burden increases, recovery is delayed.

It seems that cancer patients' hope depends on some factors, both physical (e.g., pain and energy level) and mental (anxiety and depression). Cancer patients suffer from physical and mental disturbances. They feel loss of goal, pride, and self-glory. In fact, the hope in the case of cancer care is connected to the hope of treatment. As expected, the high level of hope results in better life quality. Our findings support the outcome of van der Biessen et al. ${ }^{40}$

Shame is known as a disturbing feeling toward personal faults. From another perspective, shame is a self-conscious emotion that is aroused through self-assessment and leads to self-regulation. Shame-NSE subscale items describe bad feelings about oneself. Patients with lower degree in NSE are more likely to have personal disturbance and lower self-respect and self-compassion. They are also more likely to ruminate when they are sad. Consequently, they begin to show depressive symptoms such as disappointment and lower mental and physical performance. Shame-withdraw subscale items describe action tendencies focused on hiding or withdrawing from public. This factor has a direct negative effect on hope and an indirect negative effect on QOL. It is likely that loosing social support due to isolation leads to these negative impacts.

This survey has some limitations. First, convenient sampling restricts the generalization of findings. Second, even though caregiver- and cancer patient-related elements were discovered and implemented in the analyses of the relationship between caregiver burden, hope, and QOL, other dimensions of caregiving such as caregiver challenges, caregiver readiness, family function, and social support that might have had a role in the burden were not studied. Seven caregivers of this study were cancer patients. They were included to provide a general overview on caregiver's burden, but it is probable that their burden and QOL are different from that of other caregivers in this study. It is likely that cancer patients are sometimes their own caregivers, so their unique needs require more scrutiny. It is more helpful to perform studies on a larger population and in different centers to get better insights that support our findings.

Our study showed that cancer patients' hope has a significant relation to their QOL. In addition, we found a negative relationship between caregiver burden, hope, and QOL. This finding should be included in the interventions to offer support and notification. In addition, based on the results, interventions must also be caregiver based so as to help a faster recovery by considering caregiver's needs.

\section{Financial Support and Sponsorship}

Nil.

\section{Conflicts of Interest}

There are no conflicts of interest.

\section{Acknowledgments}

Special thanks are given to patients who participated in this study, and also to Mr. Behrouz Soruri, MA, for his critical contributions. 


\section{References}

1 Benzein EG, Berg AC. The level of and relation between hope, hopelessness and fatigue in patients and family members in palliative care. Palliat Med 2005;19(3):234-240

2 Senden C, Vandecasteele T, Vandenberghe E, et al. The interaction between lived experiences of older patients and their family caregivers confronted with a cancer diagnosis and treatment: a qualitative study. Int J Nurs Stud 2015;52(1):197-206

3 Coolbrandt A, Sterckx W, Clement P, et al. Family caregivers of patients with a high-grade glioma: a qualitative study of their lived experience and needs related to professional care. Cancer Nurs 2015;38(5):406-413

4 Ferrell B, Hanson J, Grant M. An overview and evaluation of the oncology family caregiver project: improving quality of life and quality of care for oncology family caregivers. Psychooncology 2013;22(7):1645-1652

5 Hoffmann RL, Mitchell AM. Caregiver burden: historical development. Nurs Forum 1998;33(4):5-11

6 Jeong YG, Jeong YJ, Kim WC, Kim JS. The mediating effect of caregiver burden on the caregivers' quality of life. J Phys Ther Sci 2015;27(5):1543-1547

7 Fletcher BS, Paul SM, Dodd MJ, et al. Prevalence, severity, and impact of symptoms on female family caregivers of patients at the initiation of radiation therapy for prostate cancer. J Clin Oncol 2008;26(4):599-605

8 Deshields TL, Rihanek A, Potter P, et al. Psychosocial aspects of caregiving: perceptions of cancer patients and family caregivers. Support Care Cancer 2012;20(2):349-356

9 Song JI, Shin DW, Choi JY, et al. Quality of life and mental health in family caregivers of patients with terminal cancer. Support Care Cancer 2011;19(10):1519-1526

10 Grunfeld E, Coyle D, Whelan T, et al. Family caregiver burden: results of a longitudinal study of breast cancer patients and their principal caregivers. CMAJ 2004;170(12):1795-1801

11 Schulz R, O’Brien AT, Bookwala J, Fleissner K. Psychiatric and physical morbidity effects of dementia caregiving: prevalence, correlates, and causes. Gerontologist 1995;35(6):771-791

12 Fang CY, Manne SL, Pape SJ. Functional impairment, marital quality, and patient psychological distress as predictors of psychological distress among cancer patients' spouses. Health Psychol 2001;20(6):452-457

13 Kim MK, Sim JA, Yun YH, et al. Health-related quality of life and sociodemographic characteristics as prognostic indicators of long-term survival in disease-free cervical cancer survivors. Int J Gynecol Cancer 2016;26(4):743-749

14 Duggleby W, Holtslander L, Kylma J, Duncan V, Hammond C, Williams A. Metasynthesis of the hope experience of family caregivers of persons with chronic illness. Qual Health Res 2010;20(2):148-158

15 Lin $\mathrm{HC}$, Wu $\mathrm{CH}$, Lee $\mathrm{HC}$. Risk factors for suicide following hospital discharge among cancer patients. Psychooncology 2009;18(10):1038-1044

16 Rodin G, Lo C, Mikulincer M, Donner A, Gagliese L, Zimmermann C. Pathways to distress: the multiple determinants of depression, hopelessness, and the desire for hastened death in metastatic cancer patients. Soc Sci Med 2009;68(3):562-569

17 Shun SC, Hsiao FH, Lai YH. Relationship between hope and fatigue characteristics in newly diagnosed outpatients with cancer. Oncol Nurs Forum 2011;38(2):E81-E86

18 Lin CC, Lai YL, Ward SE. Effect of cancer pain on performance status, mood states, and level of hope among Taiwanese cancer patients. J Pain Symptom Manage 2003;25(1):29-37

19 Utne I, Miaskowski C, Bjordal K, Paul SM, Rustoen T. The relationships between mood disturbances and pain, hope, and quality of life in hospitalized cancer patients with pain on regularly scheduled opioid analgesic. J Palliat Med 2010;13(3):311-318
20 Lin HR, Bauer-Wu SM. Psycho-spiritual well-being in patients with advanced cancer: an integrative review of the literature. J Adv Nurs 2003;44(1):69-80

21 Trask PC, Hsu MA, McQuellon R. Other paradigms: health-related quality of life as a measure in cancer treatment: its importance and relevance. Cancer J 2009;15(5):435-440

22 Lee SS, Chung HY, Kwon OK, Yu W. Quality of life in cancer survivors 5 years or more after total gastrectomy: a case-control study. Int J Surg 2014;12(7):700-705

23 Averill PM, Diefenbach GJ, Stanley MA, Breckenridge JK, Lusby B. Assessment of shame and guilt in a psychiatric sample: a comparison of two measures. Pers Individ Dif 2002;32:1365-1376

24 LoConte NK, Else-Quest NM, Eickhoff J, Hyde J, Schiller JH. Assessment of guilt and shame in patients with non-small-cell lung cancer compared with patients with breast and prostate cancer. Clin Lung Cancer 2008;9(3):171-178

25 Zarit SH, Reever KE, Bach-Peterson J. Relatives of the impaired elderly: correlates of feelings of burden. Gerontologist 1980;20(6):649-655

26 Chichester JW, Baumgarten M. The health of persons giving care to the elderly: A critical review of the literature. Journal of clinical epidemiology1989;42:1137-48.

27 Cohen TR, Wolf ST, Panter AT, Insko CA. Introducing the GASP scale: a new measure of guilt and shame proneness. J Pers Soc Psychol 2011;100(5):947-966

28 Tangney JP. Conceptual and methodological issues in the assessment of shame and guilt. Behav Res Ther 1996;34(9):741-754

29 Aaronson NK, Ahmedzai S, Bergman B, et al. The European Organization for Research and Treatment of Cancer QLQ-C30: a quality-of-life instrument for use in international clinical trials in oncology. J Natl Cancer Inst 1993;85(5):365-376

30 Cankurtaran ES, Ozalp E, Soygur H, Ozer S, Akbiyik DI, Bottomley A. Understanding the reliability and validity of the EORTC QLQ-C30 in Turkish cancer patients. Eur J Cancer Care (Engl) 2008;17(1):98-104

31 Tan ML, Idris DB, Teo LW, et al. Validation of EORTC QLQC30 and QLQ-BR23 questionnaires in the measurement of quality of life of breast cancer patients in Singapore. Asia Pac J Oncol Nurs 2014;1(1):22-32

32 Herth K. Abbreviated instrument to measure hope: development and psychometric evaluation. J Adv Nurs 1992;17(10):1251-1259

33 Meyers LS, Gamst G, Guarino AJ, Applied Multivariate Research: Design and Interpretation. Thousand Oaks: Sage Publications; 2006

34 Bishara AJ, Hittner JB. Testing the significance of a correlation with nonnormal data: comparison of Pearson, Spearman, transformation, and resampling approaches. Psychol Methods 2012;17(3):399-417

35 Munro BH, Plichta SB, Kelvin EA, Munro's Statistical Methods for Health Care Research. Philadelphia, PA: Wolters Kluwer, Lippincott Williams \& Wilkins; 2013

36 Blood GW, Simpson KC, Dineen M, Kauffman SM, Raimondi SC. Spouses of individuals with laryngeal cancer: caregiver strain and burden. J Commun Disord 1994;27(1):19-35

37 Oberst MT, Thomas SE, Gass KA, Ward SE. Caregiving demands and appraisal of stress among family caregivers. Cancer Nurs 1989;12(4):209-215

38 Nijboer C, Tempelaar R, Triemstra M. van den Bos GA, Sanderman R. The role of social and psychologic resources in caregiving of cancer patients. Cancer 2001;91(5):1029-1039

39 Grov EK, Fosså SD, Sørebø O, Dahl AA. Primary caregivers of cancer patients in the palliative phase: a path analysis of variables influencing their burden. Soc Sci Med 2006;63(9):2429-2439

40 van der Biessen DA, van der Helm PG, Klein D, et al. Understanding how coping strategies and quality of life maintain hope in patients deliberating phase I trial participation. Psychooncology 2018;27(1):163-170 